\title{
Factors Influencing the Service Life of Buildings
}

\author{
W.P.S. Dias
}

\begin{abstract}
The service life of a building depends mainly on its chief structural materials and the environment it is placed in. This paper collates the evidence from condition surveys conducted on some buildings with ages of up to 125 years set in a humid tropical environment, and seeks to arrive at some generalizations. Load bearing masonry walls and timber floors had performed well, as had exposed steel sections that were well maintained. Buildings with such elements could be expected to last well beyond the 'normal' design life of 60 years. If a reinforced concrete building had been exposed to a chloride source, major repairs were required after just half this design life. Carbonation depth was found to broadly obey a correlation with the square root of time. However, it is shown that both depths of carbonation and surface chloride levels can vary considerably in different parts of the same building. These findings have direct implications for both construction (in the choice of materials) and inspection (with respect to sampling and use of multiple test methods).
\end{abstract}

Keywords: Service life, durability, chlorides, carbonation, corrosion

\section{Introduction}

\subsection{The Service Life of Buildings}

The service life of structures depend on a variety of factors, such as (i) their purpose; (ii) socio-economic considerations; (iii) materials of construction; (iv) surrounding environment; and (v) degree of maintenance (Dias, 2003).

Very long service life of even up to 500 years or more would be desired for monumental buildings such as temples and churches. Public buildings such as town halls and parliament buildings could be expected to last for 100 to 200 years, whereas private structures such as offices and dwellings for perhaps 50 to 60 years. BS 7543 (1992), defines the 'normal' life of a building as 60 years. The new Eurocodes, e.g. BS EN 1992-1-1 (2008), assume this period to be a lower one of 50 years.

Socio-economic considerations impinge on the above durations, some of which tend to reduce the lifespans of buildings, while others increase them. The changing needs of various owners, and indeed the changing face of the city or area in which the building is located, may cause a building to be obsolete even before it ceases to be serviceable. In the context of the above proneness to change, most investors or builders may not want to invest in a building with an excessive service life. On the other hand, owners sometimes try to use an existing building over and above its service life, because demolition and reconstruction may force them to comply with new planning regulations. Also, once a building exceeds a certain lifespan, the owner, or even other interested parties, may wish to prolong its life further, if it is considered a national heritage.

The different materials of construction that are used in a building will give rise to different rates of deterioration. In general, steel and reinforced concrete will tend to deteriorate faster than masonry; and timber in internal environments. Heat and moisture are environmental factors that tend to accelerate deterioration. Where steel embedded concrete and structural steel are concerned, a chloride environment, inclusive of proximity to the coast, will significantly enhance corrosion.

The factors affecting service life can vary, not only from building to building, but even within a given building. For example, (i) The quality of the substructure, superstructure and even roof structure in a building may vary if different subcontractors were responsible for them; (ii) the environment a building is subjected to will vary from external elements to internal elements and also from seaward side to landward side (if it is near the coast); and (iii) different building elements may receive different degrees of maintenance, depending on their accessibility and inspectability.

\subsection{Changes in Construction Technology}

From a historical perspective, we can identify

Eng. (Prof.) W.P.S. Dias, BScEng(Hons), PhD(Lond), DIC, CEng, MIStructE, FIE(Sri Lanka), Senior Professor of Civil Engineering, Department of Civil Engineering, University of Moratuwa, Sri Lanka. 
1945 as a point at which there was a worldwide shift in building materials usage - i.e. most structural steel used for beams and columns, and timber used for floors, was replaced with reinforced concrete.

We can also identify a time around 1975 as a point at which there were a more subtle changes in the quality of building materials. There was a worldwide change in cement manufacturing processes, resulting in cements that developed greater strengths quicker (due to the increased percentage of tricalcium silicate in cements). This meant that a given strength of concrete (normally tested at an age of 28 days) could be achieved with less cement. However, concretes were now made not only with lower cement contents, but also with lower percentages of the ingredient in cement (i.e. dicalcium silicate) that contributed to longer term strength development. This resulted in a lowering of the durability properties of the concrete. There was also a worldwide scarcity of timber for construction, causing less durable species of timber to be used for construction. Although such species were chemically treated to improve durability, the efficiency of treatment may not always have been adequate.

The passage of time (especially since 1975) has of course seen increasingly greater awareness of durability issues, and these have been reflected in codes of practice, especially in those for reinforced concrete. It can therefore be argued that the greater awareness of durability issues has compensated for some of the detrimental impacts on durability described above. In this same period, building durability has been improved through the availability of good quality waterproofing materials, performance enhancing admixtures for concrete and specialist repair materials (e.g. repair mortars). However, building longevity may have decreased due to the modern practice of hiding most of the structural elements behind ceilings, paneling and facades, thus making inspection (and hence the early arresting of deterioration) more difficult.

\section{Objectives and Methodology}

The first objective of this paper is to analyse a set of condition evaluations carried out on buildings from the ages of 7 to 125 years, and to draw various lessons from that analysis regarding the factors that either increase or decrease the longevity of buildings. These evaluations have not been carried out in a random fashion, but rather in response to clients. At early ages, such evaluations are generally made only due to changes of building ownership. In mid life a need for evaluation often occurs due to unexpected deterioration. At older ages, clients request evaluations because of concern regarding the continued safety of their buildings. Many of these evaluations are based largely on visual inspection, but some of them are backed up by a reasonable degree of sampling for material properties, inclusive of durability indices (e.g. Dias, 1994; Dias and Jayanandana, 2003; Dias and Sivasubramaniam, 1989).

The second objective of this paper is to analyse some data regarding the depths of carbonation and surface chloride levels of some reinforced concrete elements or structures, because carbonation and chloride ingress are the two main mechanisms that lead to the deterioration of such structures. Considerable focus is placed on variations of such indices within the structure itself.

The carbonation depths have been obtained by spraying a $1 \%$ phenolphthalein solution onto freshly cut surfaces and noting the depth that remains colourless. The fresh cuts were made either by coring (where the core is used for a variety of other purposes such as strength testing) or by advancing a drill bit into the surface in increments of $5 \mathrm{~mm}$, spraying the phenolphthalein solution into the hole at each increment and noting the depth at which the outflowing liquid is pink in colour. The carbonation depths in a structure at a given age will help us to estimate how much longer it will take for the carbonation front to reach the reinforcement (i.e. for the 'incubation' phase to be completed), after which the likelihood of corrosion increases significantly. If the front has already passed the level of the reinforcement, it signals the need to take stringent measures for ensuring that the reinforced concrete elements are waterproof.

Procedures for determining the chloride profile within the concrete cover zone are well documented (e.g. see de Rooij and Polder, 2004). This can be done by using extracted cores, slicing them and obtaining the chloride contents at various depths. It is then possible to predict the time at which the chloride content at the level of the reinforcement will reach a certain threshold value for corrosion initiation by using the surface chloride concentration and the diffusion coefficient obtained from the 
chloride profile. However, obtaining the diffusion coefficient in this way is difficult and tedious (de Rooij and Polder, 2004).

As such, the above modeling can also be done by using values published in the literature (e.g. Bentz and Thomas, 2012). These depend on the water/cement ratio (which affects the initial diffusion coefficient) and type of cement (which affects the age dependent variation of that coefficient). Whatever method is used, the surface chloride content must be obtained from the structure being examined. Published literature also gives guidance regarding the rates of surface chloride build-up. However, such broad generalizations may not be accurate, and there could also be variations depending on the micro environment.

The surface chloride contents for the case studies in this paper have been obtained by taking the surface layer of the element, whether a plaster coating (of around $10 \mathrm{~mm}$ thickness) or a surface slice of $5 \mathrm{~mm}$ from extracted cores, and determining either the total or water soluble chloride content in that layer by acid or water extraction respectively.

\section{Case Studies of Deterioration}

Table 1 gives a few cases of buildings that were inspected for condition evaluation over a period ranging from 1988 to 2011, with the age of the building at inspection given in parentheses. They are listed in inverse order of year of construction, which also happens to correspond to increasing age when the inspection was made. The cases can be divided into three broad categories, separated by bold horizontal lines in Table 1 . The 7 and 12 year old buildings, which do not show any visible deterioration, fall into the first category.

In the next category are buildings of ages 25 to 30 years where distress of varying degree has occurred in reinforced concrete elements, due to chloride induced corrosion. The chloride source for both the Hotel Sunflower and Buddhist Girls' School is sea spray. It should be noted that the much greater corrosion in the latter is due to poor construction. For the Puttalam Cement Works, the chloride source was the groundwater used during construction (Dias and Jayanandana, 2003), and for the Bandaranaike Wing of the Colombo General Hospital, contamination from the toilets (Dias and Sivasubramaniam, 1989). This suggests that serious repair work may become necessary after around 30 years if reinforced concrete elements of a building are exposed to a chloride source.

In the last category are buildings that have survived for 65 to 125 years. It should be noted that the main structural elements are not of reinforced concrete in these buildings; note that these have been constructed prior to the year 1945, alluded to before. Two of the 100 year old buildings had masonry loadbearing walls and timber floors too - i.e. no steel at all. This combination is arguably the best combination for ensuring long service life. The rest of the buildings in this category are steel framed, with reinforced concrete floors or roofs. In almost all cases the reinforced concrete elements experienced significant corrosion, especially roofs and toilet areas. The Grand Hotel displayed only minimal deterioration in the slabs above the kitchens, which are moist and humid environments. In general hotel buildings tend to be well maintained, with defects attended to promptly. Steel columns and beams that were exposed (and hence easily painted) performed very well, as seen in the 125 year old Gaffoor Building (Figure 1), where the contrast with the reinforced concrete slab is stark. On the other hand, encasing the columns in concrete (Figure 2) and the beams in a mesh and plaster covering (Figure 3) resulted in undetected corrosion of the structural elements.

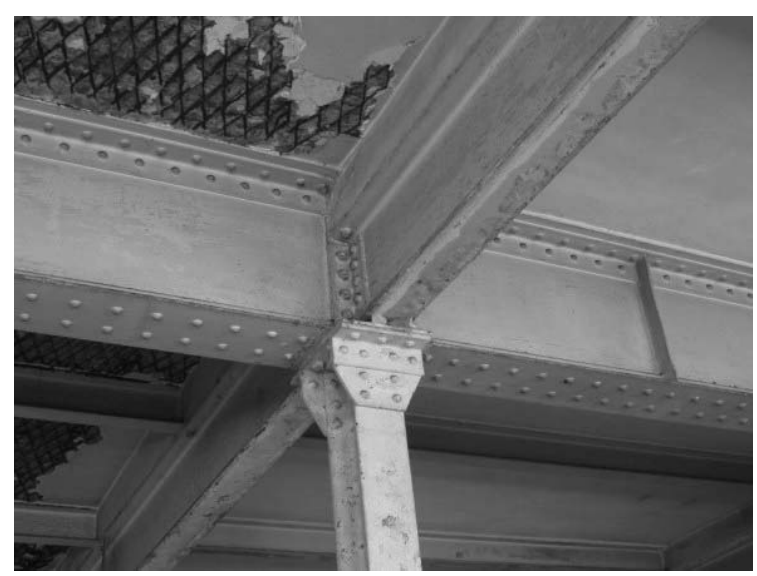

Figure 1 - Exposed steel columns and beams in the 125 year old Gaffoor Building

\section{Depths of Carbonation}

Apart from a chloride environment, referred to above, reinforced concrete in all environments will experience carbonation. When the carbonation front reaches the reinforcement, the chemical protection given to it by the concrete 
Table 1 - Analysis of Condition Evaluations

\begin{tabular}{|c|c|c|c|c|}
\hline Building & $\begin{array}{c}\text { Year \& } \\
\text { Age (yrs) }\end{array}$ & $\begin{array}{l}\text { Building } \\
\text { Type }\end{array}$ & Deterioration & Comments \\
\hline $\begin{array}{l}\text { Smart Shirts } \\
\text { Factory, } \\
\text { Katunayake }\end{array}$ & $\begin{array}{c}1991 \\
(7)\end{array}$ & $\begin{array}{l}\text { RC frame } \\
\text { and slabs }\end{array}$ & Not apparent & \\
\hline $\begin{array}{l}\text { Tourist Board } \\
\text { Building, } \\
\text { Colombo } 4\end{array}$ & $\begin{array}{c}1982 \\
(12)\end{array}$ & $\begin{array}{l}\text { RC frame } \\
\text { and slabs }\end{array}$ & Not apparent & \\
\hline $\begin{array}{l}\text { Buddhist Girls' } \\
\text { School, Mt. } \\
\text { Lavinia }\end{array}$ & $\begin{array}{l}1977 \\
(25)\end{array}$ & $\begin{array}{l}\text { RC frame } \\
\text { and slabs }\end{array}$ & $\begin{array}{l}\text { Columns and sunshades } \\
\text { badly corroded }\end{array}$ & $\begin{array}{l}\text { Location close to coast; } \\
\text { poor quality construction }\end{array}$ \\
\hline $\begin{array}{l}\text { Hotel Sunflower, } \\
\text { Negombo }\end{array}$ & $\begin{array}{l}1974 \\
(25) \\
\end{array}$ & $\begin{array}{l}\text { RC frame } \\
\text { and slabs }\end{array}$ & Some corrosion & Location close to coast \\
\hline $\begin{array}{l}\text { Puttalam Cement } \\
\text { Works }\end{array}$ & $\begin{array}{l}1970 \\
(28)\end{array}$ & $\begin{array}{l}\text { RC frame } \\
\text { and slabs }\end{array}$ & $\begin{array}{l}\text { Some buildings badly } \\
\text { corroded }\end{array}$ & $\begin{array}{l}\text { High chloride levels in } \\
\text { groundwater used for } \\
\text { concreting }\end{array}$ \\
\hline $\begin{array}{l}\text { Bandaranaike } \\
\text { Wing, Colombo } \\
\text { General Hospital } \\
\end{array}$ & $\begin{array}{c}1958 \\
(30)\end{array}$ & $\begin{array}{l}\text { RC frame } \\
\text { and slabs }\end{array}$ & $\begin{array}{l}\text { Severe corrosion in toilet } \\
\text { area slabs }\end{array}$ & $\begin{array}{l}\text { High chloride levels } \\
\text { through operation }\end{array}$ \\
\hline $\begin{array}{l}\text { Baur's } \\
\text { Tenemants, } \\
\text { Grandpass Road }\end{array}$ & $\begin{array}{c}1936 \\
(65)\end{array}$ & $\begin{array}{l}\text { Steel frame; } \\
\text { RC slabs } \\
\text { and roof }\end{array}$ & $\begin{array}{l}\text { RC roof badly corroded; } \\
\text { also open corridor and } \\
\text { toilet slabs }\end{array}$ & Poorly maintained \\
\hline $\begin{array}{l}\text { Angoda Mental } \\
\text { Hospital }\end{array}$ & $\begin{array}{c}1925 \\
(72) \\
\end{array}$ & $\begin{array}{c}\text { Steel frame, } \\
\text { RC slabs }\end{array}$ & $\begin{array}{l}\text { Toilet area slabs badly } \\
\text { corroded }\end{array}$ & Poorly maintained \\
\hline $\begin{array}{l}\text { Grand Hotel, } \\
\text { Nuwara Eliya }\end{array}$ & $\begin{array}{l}1911 \\
(100)\end{array}$ & $\begin{array}{l}\text { Masonry; } \\
\text { timber \& RC } \\
\text { floors }\end{array}$ & $\begin{array}{l}\text { Some deterioration in } \\
\text { slabs above kitchens }\end{array}$ & $\begin{array}{l}\text { Generally cool } \\
\text { environment; well } \\
\text { maintained. }\end{array}$ \\
\hline $\begin{array}{l}\text { Central Point, } \\
\text { Colombo Fort }\end{array}$ & $\begin{array}{l}1911 \\
(100)\end{array}$ & $\begin{array}{l}\text { Steel frame; } \\
\text { RC slabs } \\
\text { and roof }\end{array}$ & $\begin{array}{l}\text { Corrosion in internal } \\
\text { cased columns and roof }\end{array}$ & \\
\hline $\begin{array}{l}\text { Institute of } \\
\text { Aesthetic Studies, } \\
\text { Colombo } 7\end{array}$ & $\begin{array}{l}1899 \\
(100)\end{array}$ & $\begin{array}{c}\text { Masonry; } \\
\text { timber floor; } \\
\text { RC roof }\end{array}$ & $\begin{array}{l}\text { All RC components } \\
\text { corroded }\end{array}$ & \\
\hline $\begin{array}{l}\text { Gaffoor Building, } \\
\text { Colombo Fort }\end{array}$ & $\begin{array}{l}1886 \\
(125)\end{array}$ & $\begin{array}{l}\text { Steel frame } \\
\text { \& roof; RC } \\
\text { slabs }\end{array}$ & Severe corrosion in slabs & \\
\hline
\end{tabular}

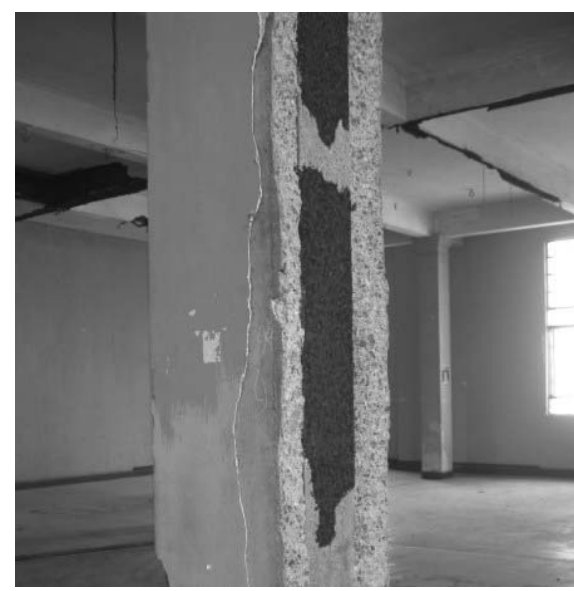

Figure 2 - Significant corrosion in concrete encased steel internal column in Central Point building

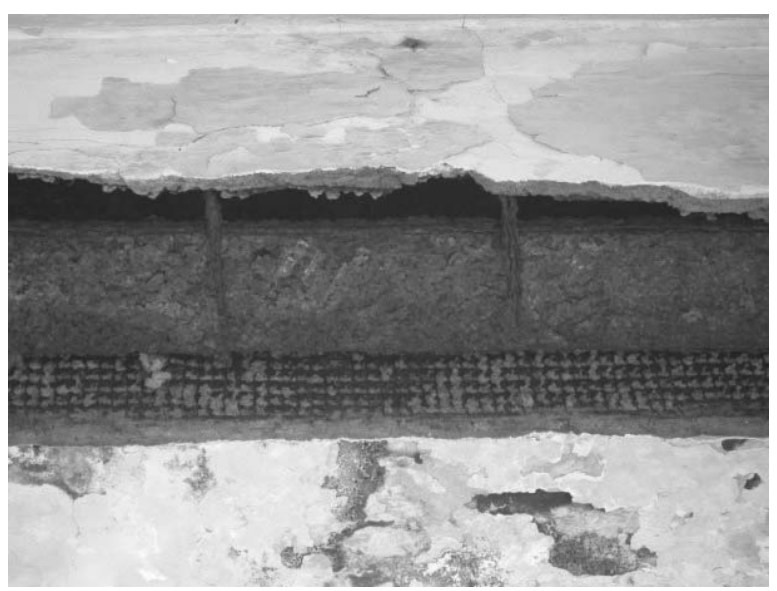

Figure 3 - Corrosion in steel floor beam covered by wire mesh and plaster in Central Point building 
will be lost, and corrosion will take place, especially in a moist or wet environment. The depth of carbonation is considered to be a function of the square root of time. Figure 4 gives a relationship for these two entities (the trend line is not forced through the origin) for some of the buildings in Table 1 together with a few others. Such a universal relationship will not strictly be possible for concretes of various qualities, and even moisture conditions. However, since most of the concretes are of around grade 20 quality, Figure 4 could be used to obtain approximately the likely carbonation depths in concretes of various ages.

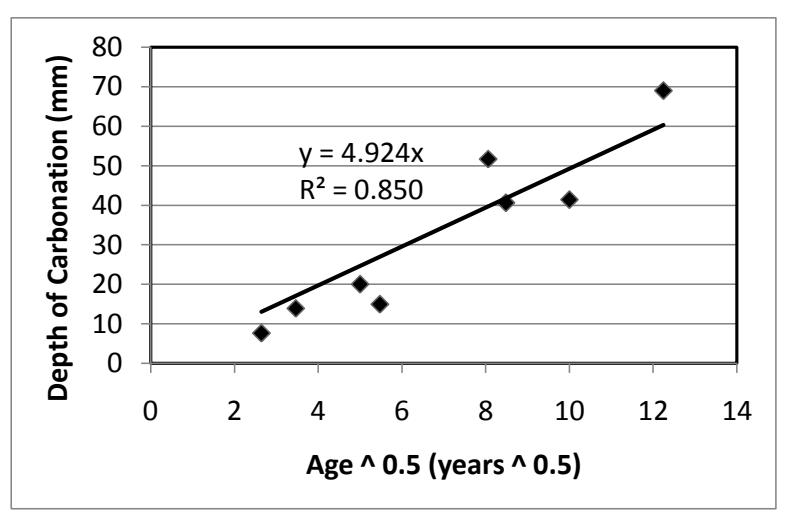

Figure 4 - Carbonation depth as a function of the square root of time

The slope of a logarithmic plot between depth of carbonation (d) and time (t) will give an estimate of the exponent ' $n$ ', in the relationship $\mathrm{d}=\mathrm{k}(\mathrm{t})^{\mathrm{n}}$, where $\mathrm{k}$ is a constant. Such a plot in Figure 5 gives the exponent as 0.69 , somewhat higher than the usually adopted value of 0.5 (i.e. the square root of time law). This may be due to the possibility that the older concretes have a higher $\mathrm{k}$ value than the more recent ones (Richardson, 1988). A plot using only the first four data points in Figure 5 (corresponding to a maximum age of 30 years and years of construction from 1958 to 1991) gives the expected slope of 0.52 . It should be noted that these four data points all fall below the regression line in Figure 4.

Figure 5 is based on the average carbonation depths from the buildings surveyed. There can however be significant differences between various areas in a building. For example, Figure 6 shows the differences in depths of carbonation for toilet areas compared to corridor ones in the 30 year old Bandaranaike Wing of the Colombo General Hospital (Dias and Sivasubramaniam, 1989). The corridor areas were more carbonated because the concrete was dry, whereas the toilet areas were less carbonated because the concrete was wet, with 4 zero values too. However, there is greater scatter in the values for the toilets, inclusive of some high values - these regions would be very susceptible to corrosion if the carbonation depth exceeds the cover provided, because of the wet conditions. The phenomena of zero carbonation depths and widespread variation in such depths within a building have been reported before (Roy et al, 1996).

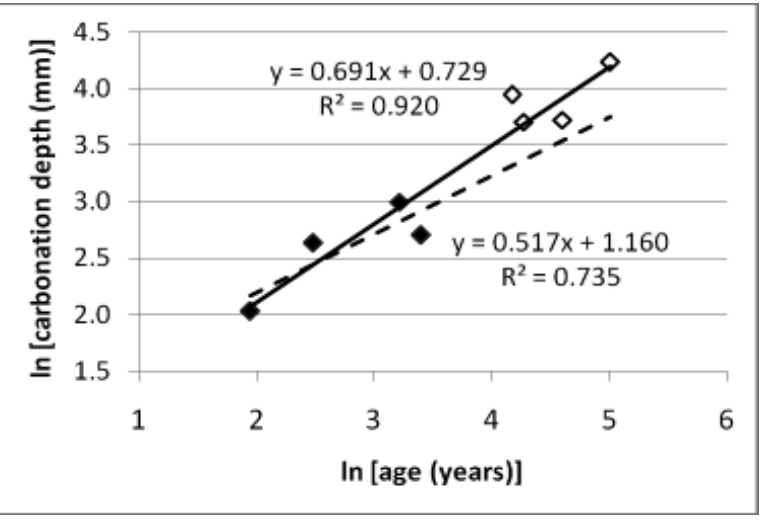

Figure 5 - Determining the exponent ' $n$ ' in the expression $\mathbf{d}=\mathbf{k t}^{\mathbf{n}}$

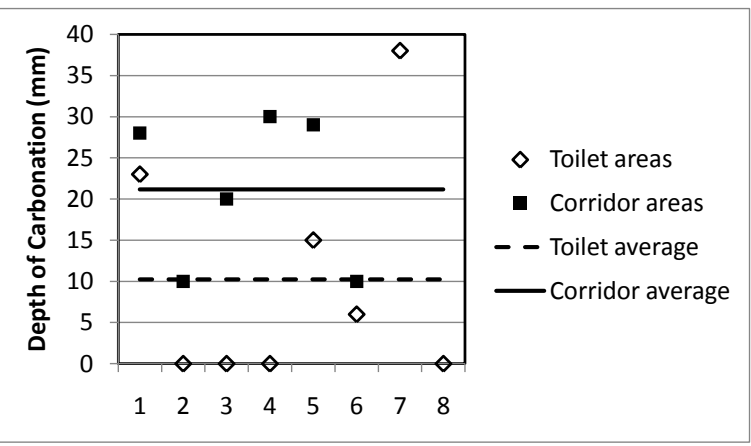

Figure 6 - Carbonation depths at Bandaranaike Wing, Colombo General Hospital

\section{Surface Chloride Levels}

Figure 7 gives the variation in the rate of surface chloride build up for different elements in 3 coastal hotels of varying ages. There is a clear difference between the rates for interior and exterior elements, with the former being significantly less than the latter and displaying much less scatter. It should be noted that these rates have been obtained from the water soluble average chloride contents in plasters of thickness around $10 \mathrm{~mm}$. The published literature for total surface chloride build up rates on concrete surfaces can range from $0.004 \%$ to more than $0.1 \%$ by weight of concrete 
per year, depending on the proximity to the coast (Bentz and Thomas, 2012).

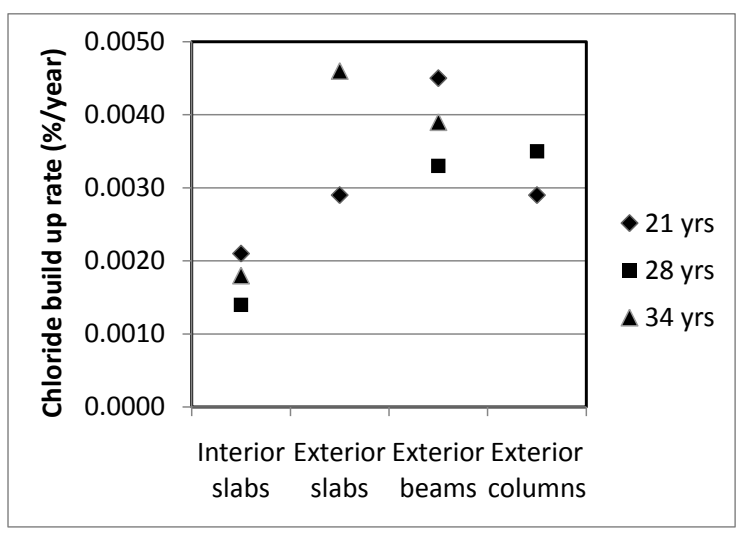

Figure 7 - Surface chloride build up rates at 3 coastal hotels of different ages

Another example of within structure surface chloride level variations is given in Table 2 for the 100 year old Central Point building in Colombo Fort, a capital port city. These total (i.e. acid soluble) chloride levels were obtained from $5 \mathrm{~mm}$ thick slices cut from the bottom surfaces of 4 cores taken at each floor level. The very high levels in the fourth and fifth floors compared to the lower ones may be due to the shielding of the lower floors by surrounding buildings. It may also be due to sea spray contaminated rainwater entering the upper floor levels through observed leaks in the concrete roof. The evidence for the chloride level variation is confirmed by the degree of corrosion observed in the mesh reinforcement embedded in those cores. Figures 8(a), 8(b) and 8 (c) give examples of the degree of corrosion defined as low (L), medium (M) and high (H).

\section{Concluding Discussion - Implications for Practice}

The case studies in Table 1 indicate that if very long service life is required, consideration should be given to using construction materials such as masonry for walls, timber for floors and exposed (not encased) steel sections for columns and beams. Such materials, especially the steel sections, will however require continuous maintenance. Reinforced concrete, although very popular after around 1945, is good for normal life buildings (i.e. 50 to 60 years) that need little maintenance.

If reinforced concrete is used for buildings in chloride environments, provision will have to be made for improved design (e.g. greater cover and better quality concrete); else the buildings may reach only around half their expected service life.

\section{Table 2 - Surface chloride content variations in Central Point building}

\begin{tabular}{lcc}
\hline Floor & $\begin{array}{c}\text { Chloride content } \\
\text { (w/w \%) } \\
\text { (range, average) }\end{array}$ & $\begin{array}{c}\text { Corrosion } \\
\text { Level } \\
(\mathbf{H}, \mathbf{M}, \mathrm{L})\end{array}$ \\
\hline Ground & $0.02-0.04(0.03)$ & $\mathrm{L}, \mathrm{L}, \mathrm{L}, \mathrm{L}$ \\
First & $0.03-0.05(0.04)$ & $\mathrm{L}, \mathrm{L}, \mathrm{L}, \mathrm{L}$ \\
Second & $0.03-0.04(0.038)$ & $\mathrm{L}, \mathrm{L}, \mathrm{L}, \mathrm{M}$ \\
Third & $<0.01-0.07(0.045)$ & $\mathrm{L}, \mathrm{L}, \mathrm{L}, \mathrm{H}$ \\
Fourth & $0.04-0.31(0.150)$ & $\mathrm{L}, \mathrm{L}, \mathrm{M}, \mathrm{H}$ \\
Fifth & $0.07-0.50(0.210)$ & $\mathrm{H}, \mathrm{H}, \mathrm{H}, \mathrm{H}$ \\
\hline
\end{tabular}

When conducting forensic investigations on buildings, care should be taken to ensure that samples are taken from various exposure conditions, because carbonation depths and surface chloride levels can differ considerably from one part of a building to another. This will enable more nuanced strategies to be proposed for continued use.

Greater confidence in the sampling can be obtained by combining and comparing different test results. For example, the surface chloride levels can be compared with the degree of corrosion in embedded reinforcement. Comparisons can also be made between the structure being investigated and the accumulated data from buildings in a

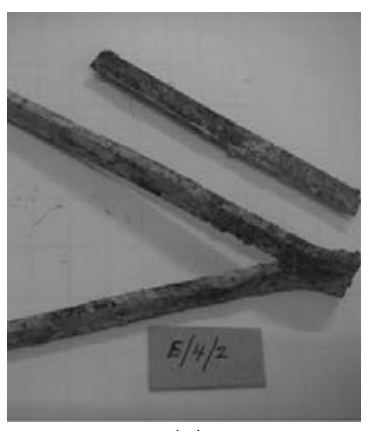

(a)

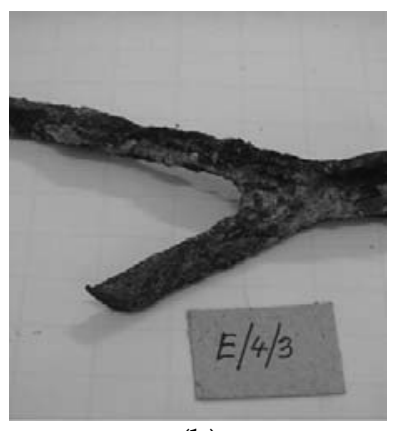

(b)

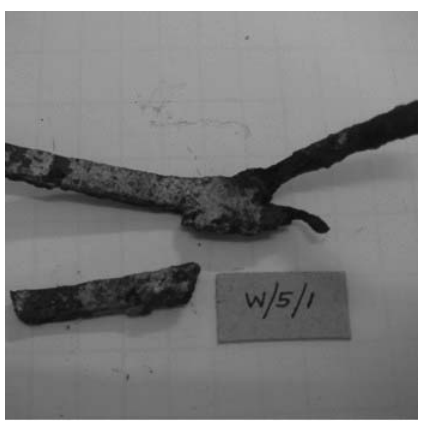

(c)

Figure 8 - Degrees of corrosion in embedded reinforcement: (a) Low; (b) Medium; (c) High 
similar environment. For example, the estimate for the carbonation related incubation phase duration can be obtained both from the building concerned and also from an overall curve for buildings of varying ages

\section{References}

1. Bentz, E. C. and Thomas, M. D. A. (2012). Life-365 Service life Prediction Model for Reinforced Concrete Exposed to Chlorides: Computer Program and user manual, v. 2.1. Life-365 Consortium II, January.

2. BS 7543: 1992. Guide to Durability of Buildings and Building Elements, Products and Components. British Standards Institution, Milton Keynes.

3. BSEN 1992: Part 1-1: 2008 Eurocode 2: Design of concrete structures: General rules and rules for buildings. British Standards Institution, Milton Keynes.

4. de Rooij, M. R. and Polder, R. B. (2004). What Diffusion Coefficient is used for Chloride Diffusion Modeling? In Advances in Concrete through Science and Engineering. RILEM International Symposium, March.
5. Dias, W. P. S. (1994). Structural Appraisal of Reinforced Concrete Buildings from In-Situ Material Properties - Some Issues and Insights. Transactions, Institution of Engineers, Sri Lanka, pp. 129-145.

6. Dias, W. P. S. (2003). Useful life of Buildings. University of Moratuwa, Moratuwa, June. http://www.slaasmb.org/USEFUL LIFE OF BUILDINGS.doc. Accessed 23/03/2012.

7. Dias, W. P. S. and Jayanandana, A. D. C. (2003). Condition Assessment of a Deteriorated Cement Works. ASCE Journal of Performance of Constructed Facilities. Vol. 17, No. 4, pp. 188-195.

8. Dias, W. P. S. and Sivasubramaniyam, S. (1989). Assessment of Floor Slabs in the Bandaranaike Wing of the Colombo General Hospital. Engineer (Sri Lanka). September, pp. 27-36.

9. Richardson, M. G. (1988). Carbonation of Reinforced Concrete: Its Causes and Management. Citis, London.

10. Roy, S. K., Northwood, D. O. and Poh, K. B. (1996). Effect of Plastering on the Carbonation of a 19 year old Reinforced Concrete Building. Journal of Construction and Building Materials, Vol. 10, No. 4, pp. 267-272. 